\title{
The attenuation of seismic intensity in the Etna region and comparison with other Italian volcanic districts
}

\author{
Raffaele Azzaro $\left({ }^{1}\right)$, M. Serafina Barbano $\left({ }^{2}\right)$, Salvatore D’Amico $\left({ }^{1}\right)$ and Tiziana Tuvè $\left({ }^{1}\right)$ \\ (1) Istituto Nazionale di Geofisica e Vulcanologia, Sezione di Catania, Italy \\ ${ }^{(2)}$ Dipartimento di Scienze Geologiche, Università degli Studi di Catania, Italy
}

\begin{abstract}
A detailed analysis of the intensity attenuation in the Etna and other Italian volcanic districts, was performed using the most recent and complete intensity datasets. Attenuation laws were derived through empirical models fitting $\Delta I$ (the difference between epicentral $I_{0}$ and site $I_{x}$ intensities) average values versus hypocentral site distances by the least-square method. The huge amount of data available for the Etna area allowed us to elaborate bi-linear and logarithmic attenuation models, also taking source effects into account. Furthermore, the coefficients of the Grandori formulation have been re-calculated to verify the ones previously defined for seismic hazard purposes. Among the tested relationships, the logarithmic one is simple and fairly stable, so it was also adopted for the other volcanic Italian areas. The analysis showed different attenuation trends: on the one hand, Etna and Ischia show the highest decay of intensity $(\Delta I=4)$ in the first $20 \mathrm{~km}$; on the contrary, the Aeolian Islands and Albani Hills present a slight intensity attenuation $(\Delta I=2)$ at $20 \mathrm{~km}$ from the hypocentre; finally, Vesuvius seems to have an intermediate behaviour between the two groups. The proposed regionalization gives a significantly better image of near-field damage in volcanic regions and is easily applicable to probabilistic seismic hazard analyses.
\end{abstract}

Key words macroseismic intensity - attenuation Mt. Etna - Italian volcanic areas

\section{Introduction}

In active volcanic areas the attenuation of macroseismic intensity with distance is usually higher than in tectonic zones. This behaviour of seismic energy propagation is due both to physical properties of the medium, which is strongly fractured and with a very marked anisotropy at short distances (Del Pezzo et al., 1987; Mayeda et al., 1992; Bianco et al., 1999; Ciccotti et al.,

Mailing address: Dr. Raffaele Azzaro, Istituto Nazionale di Geofisica e Vulcanologia, Sezione di Catania, Piazza Roma 2, 95123 Catania, Italy; e-mail: azzaro@ct.ingv.it
2000; Martinez-Arevalo et al., 2003; Novelo-Casanova and Martínez-Bringas, 2005), and to features of the seismicity itself, characterised by moderate magnitudes and shallowness of foci (Vilardo et al., 1996; Del Pezzo et al., 2004; Patanè and Giampiccolo, 2004). In the Etna region, for instance, earthquakes producing severe damage or even destruction (epicentral intensity up to X EMS-98) are associated with magnitudes less than 4.8 and depths above $3 \mathrm{~km}$ (Azzaro, 2004). As a result, the highest intensity areas are very small - usually narrow zones up $5 \mathrm{~km}$ long and 1 $\mathrm{km}$ wide astride the seismogenic source - and the effects disappear quickly in some twenty kilometres, with a strong attenuation of the seismic energy in a direction orthogonal to the fault. So, the attenuation relationships of macroseismic intensity used in Italy for purposes of seismic hazard assessment (Grandori et al., 1987; Gasperini, 2001; Albarello and D'Amico, 2004) cannot be applied 
in volcanic districts, since they predict a lower attenuation rate with epicentral distance, inducing an overestimation of the expected intensities.

In general, formulas proposed to define the attenuation of ground-shaking parameters with distance are based on seismic wave propagation or empirical models. Most relationships derived from empirical approaches use logarithm and root functions (e.g., Blake, 1941; Cornell, 1968). A comprehensive review of studies on attenuation laws is reported in Gasperini (2001).

In Italy, the Grandori et al. (1987) relationship has been used for seismic hazard assessment (Slejko et al., 1998). In this framework, Peruzza (2000) calculated different coefficients of Grandori relationship using just one reference earthquake for each seismogenic zone of Italy defined in the ZS4 model (Meletti et al., 2000), volcanic areas included. This approach has, however, the weakness of being based on a restricted dataset for every single seismogenic zone (i.e. the intensity distribution of the reference earthquake), with possible biases due to source mechanism, radiation pattern, site response etc. Berardi et al. (1994) proposed another empirical law, the Cubic Root Attenuation Model (CRAM), employed in some software to compute seismic hazard using site observations (Magri et al., 1994). Lately, Albarello and D'Amico (2004) elaborated a new attenuation relationship taking into account both epicentral intensity and hypocentral distance.

The aim of this paper is to obtain intensity attenuation laws derived from empirical models that best fit data using the difference between epicentral and site intensities $(\Delta I)$, to be applied at a local scale in Italian volcanic districts (fig. 1), referring to the latest Italian seismogenic zone ZS9 (Gruppo di Lavoro, 2004). For the Etna area, in particular, the large amount of intensity data has allowed us to analyse in detail variations in the attenuation behaviour according to different laws.

\section{Dataset}

\subsection{Etna area}

The intensity data, used to calculate ad hoc intensity-distance relationships, were extracted from the macroseismic catalogue specifically compiled for the Mt. Etna region by Azzaro et al. (2000, 2002, 2006). It provides an extensive and homogenous dataset including in all 1778 earthquakes occurring from 1832 to present, 195 of which are above the damage threshold ( $I \geq \mathrm{V}$-VI EMS-98). For our analysis, only the events characterised by epicentral intensity $I_{0} \geq$ VII and by a number of macroseismic observations $N_{i p} \geq 10$ were selected, obtaining a subset of 24 earthquakes (table I). The intensity database used in this study consists of 813 site observations.

Figure 2 shows the epicentral distribution of the selected earthquakes with the relative intensity data points in the ZS936. The destructive and severely damaging events, with macroseismic magnitude $M_{m} \geq 3.7$ according to Azzaro and Barbano (1997), are mostly located in the eastern flank of the volcano which is crossed by the main seismogenic faults of the area (Azzaro, 2004), whereas only a few shocks occur outside this sector. As shown by instrumental data, the major seismicity (duration magnitude $M_{d} \geq 3.4$ ) occurring in the eastern flank of Etna is extremely shallow, with hypocentres less than $2 \mathrm{~km}$ in depth (fig. 3).

\subsection{Other volcanic districts (Aeolian Islands, Ischia, Vesuvius and Albani Hills)}

Specific earthquake catalogues for the other Italian volcanic areas have not been compiled so far and therefore we referred to the national seismic catalogue (CPTI Working Group, 2004). For the investigated districts this catalogue reports several earthquakes, but the events whose dataset of macroseismic observations is indeed suitable for studying attenuation is rather limited, so we have integrated data with earthquakes not included in the seismic catalogue.

For the Aeolian Islands only the earthquakes originating inside the volcanic sector (in bold in fig. 1) have been considered, discarding the tectonic events located in the Gulf of Patti and the Peloritani Mts. For this reason, we have not included in our analysis the 1978 earthquake which was chosen by Peruzza (2000) as a reference for calibrating the attenuation law of this area. As a result, we have selected 6 earthquakes with $I_{0} \geq \mathrm{VI}$ and $N_{i p} \geq 10$ (table II), 5 reported in the DOM database (Monachesi and Stucchi, 1997) and one 


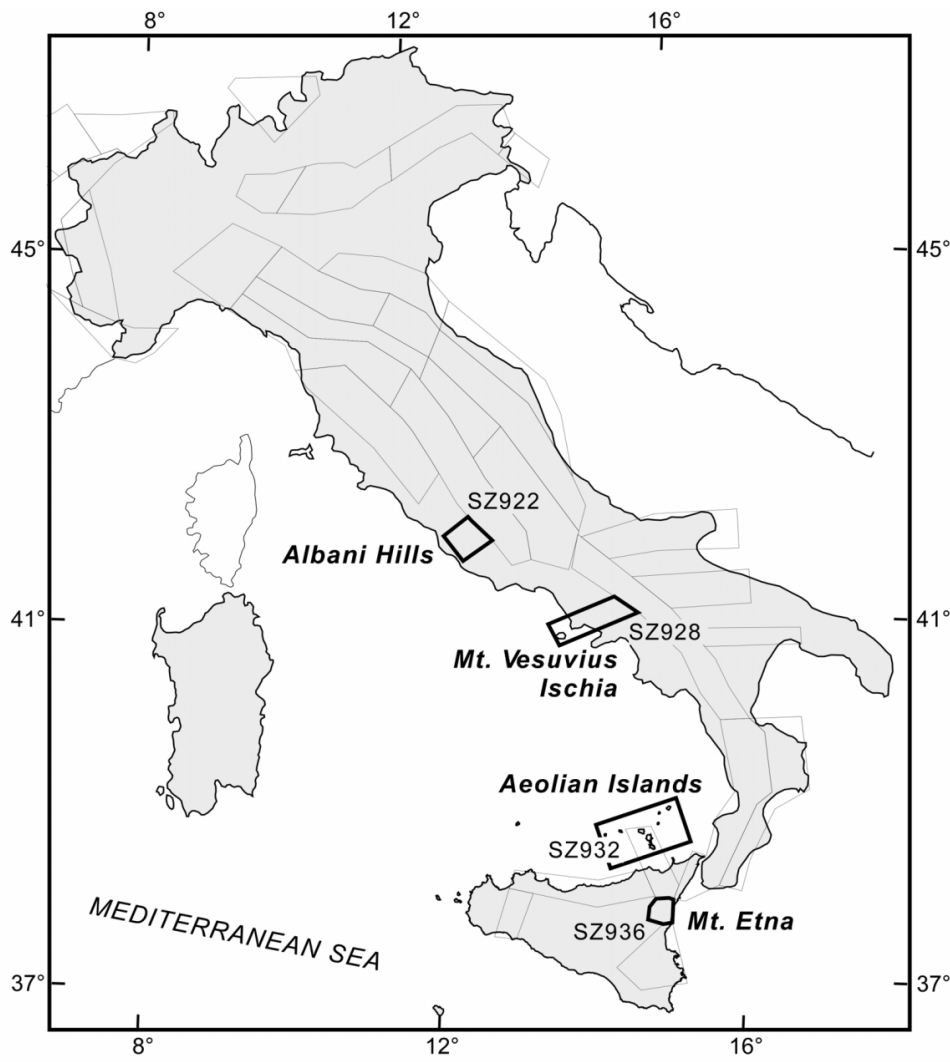

Fig. 1. Location of the studied volcanic areas (thick boxes) in the framework of the seismogenic zoning (thin polygons) used in the latest Italian seismic hazard map (Gruppo di Lavoro, 2004).

Table I. Dataset of the earthquakes selected for the Etna area. $N_{i p}$, number of intensity data points; $I_{0}$, epicentral intensity; $M_{m}$, macroseismic magnitude, calculated by the intensity-magnitude relationship from Azzaro and Barbano (1997); $M_{a w}$, moment magnitude from CPTI Working Group (2004); * magnitude from surface waves Ms (Margottini, 1993). Source of data: 1) Azzaro et al. (2000); 1a) Azzaro et al. (2006).

\begin{tabular}{|c|c|c|c|c|c|c|c|c|c|c|c|c|c|c|}
\hline Year & Month & Day & Hour & Min & $N_{i p}$ & $I_{0}$ & $M_{m}$ & $M_{d}$ & $M_{L}$ & $M_{a w}$ & Epicentral area & Lat & Long & Ref. \\
\hline 1865 & 7 & 19 & 01 & 00 & 31 & IX & 4.5 & & & 5.0 & Fondo Macchia & 37.702 & 15.153 & 1 \\
\hline 1865 & 8 & 19 & 12 & 30 & 15 & VIII & 4.1 & & & & S. M. Ammalati & 37.641 & 15.165 & 1 \\
\hline 1879 & 6 & 17 & 06 & 50 & 25 & VIII-IX & 4.3 & & & 5.0 & Bongiardo & 37.678 & 15.143 & 1 \\
\hline 1889 & 12 & 25 & 17 & 23 & 25 & VII-VIII & 3.9 & & & 4.8 & S. M. Ammalati & 37.651 & 15.156 & 1 \\
\hline 1894 & 8 & 8 & 05 & 16 & 43 & VIII-IX & 4.3 & & & 5.2 & Mazzasette & 37.653 & 15.110 & 1 \\
\hline 1898 & 5 & 14 & 04 & 45 & 20 & VII-VIII & 3.9 & & & 4.9 & S. M. Licodia & 37.615 & 14.889 & 1 \\
\hline 1907 & 12 & 7 & 21 & 28 & 18 & VII-VIII & 3.9 & & & 4.8 & Fiandaca & 37.632 & 15.134 & 1 \\
\hline 1909 & 10 & 21 & 16 & 48 & 13 & VII & 3.7 & & & 4.3 & S. G. Bosco & 37.655 & 15.162 & 1 \\
\hline 1911 & 10 & 15 & 08 & 52 & 41 & VIII-IX & 4.3 & & $4.5^{*}$ & 5.3 & Fondo Macchia & 37.699 & 15.154 & 1 \\
\hline
\end{tabular}


Table I (continued).

\begin{tabular}{|c|c|c|c|c|c|c|c|c|c|c|c|c|c|c|}
\hline Year & Month & Day & Hour & Min & $N_{i p}$ & $I_{0}$ & $M_{m}$ & $M_{d}$ & $M_{L}$ & $M_{a w}$ & Epicentral area & Lat & Long & Ref. \\
\hline 914 & 5 & 8 & 18 & 01 & 79 & IX-X & 4.7 & & $4.9^{*}$ & 5.3 & Lin & 37.659 & 15.149 & 1 \\
\hline 20 & 9 & 26 & 02 & 56 & 15 & VII-VIII & 3.9 & & & 4.6 & Codavolpe & 37.713 & 15.161 & 1 \\
\hline 1952 & 3 & 19 & 08 & 13 & 98 & VII-VIII & 3.9 & & $4.9 *$ & 5.2 & Linera & 37.660 & 15.147 & 1 \\
\hline 1971 & 4 & 21 & 16 & 30 & 11 & VIII & 4.1 & 3.5 & 4.0 & 4.2 & Fondo Macchia & 37.714 & 15.148 & 1 \\
\hline 1973 & 8 & 3 & 19 & 49 & 35 & VII & 3.7 & 3.9 & & 4.2 & S.M. Ammalati & 37.650 & 15.157 & 1 \\
\hline 73 & 8 & 18 & 22 & 38 & 18 & & & 3.7 & & & & & 65 & 1 \\
\hline 1984 & 6 & 19 & 15 & 19 & 46 & VI & 3.7 & 3.4 & & 4.4 & Fian & 37.636 & 15.131 & 1 \\
\hline 1984 & 10 & 19 & 17 & 43 & 102 & VII & 3.7 & 4.2 & 3.5 & & Zafferana Etnea & 37.694 & 15.103 & 1 \\
\hline 984 & 10 & 25 & 01 & 11 & 105 & VIII & 4.1 & 3.9 & & 4.7 & Fleri & 37.660 & 15.095 & 1 \\
\hline 985 & 12 & 25 & 02 & 39 & 10 & VII & 3.7 & 3.3 & & & Piano Provenzana & 37.8 & 15.048 & 1 \\
\hline 1986 & 2 & 2 & 16 & 10 & 55 & VII & 3.7 & 3.5 & & & S.G. Bosco & 37.653 & 15.163 & 1 \\
\hline 1986 & 10 & 29 & 23 & 18 & 35 & VII & 3.7 & 4.0 & & 4.4 & Piano Provenzana & 37.806 & 15.051 & 1 \\
\hline 1989 & 1 & 29 & 07 & 30 & 68 & & 3.7 & 4.1 & 3.3 & 4.5 & Codavolpe & 37.705 & 15.165 & 1 \\
\hline 2002 & 10 & 27 & 02 & 50 & 17 & VIII & 4.1 & 4.2 & 4.8 & & Piano Provenzana & 37.803 & 15.055 & $1 \mathrm{a}$ \\
\hline 2002 & 10 & 29 & 10 & 02 & 38 & VIII & 4.1 & 4.4 & 4.5 & 4.8 & Bongiardo & 37.674 & 15.143 & $1 \mathrm{a}$ \\
\hline
\end{tabular}

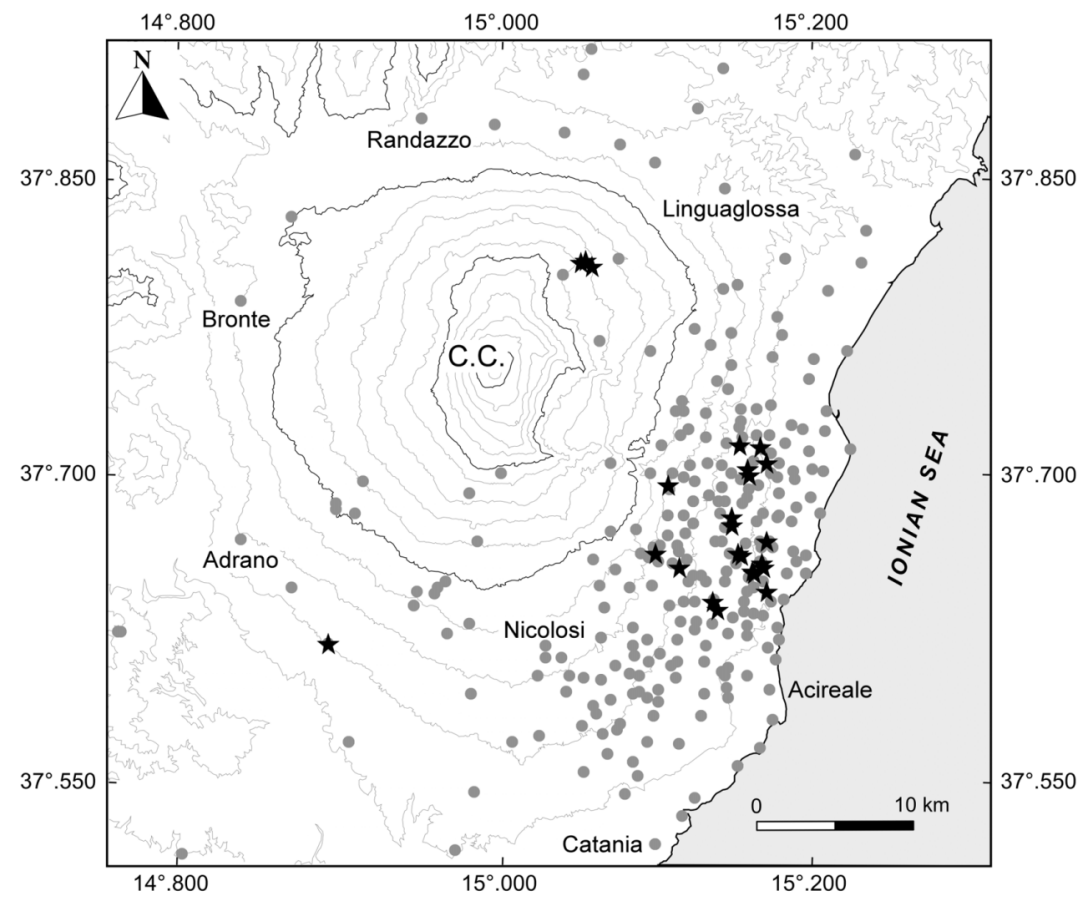

Fig. 2. Distribution of the epicentres (black stars) and related 813 site intensity observations (grey circles) of the 24 earthquakes used for the Etna region (listed in table I). 


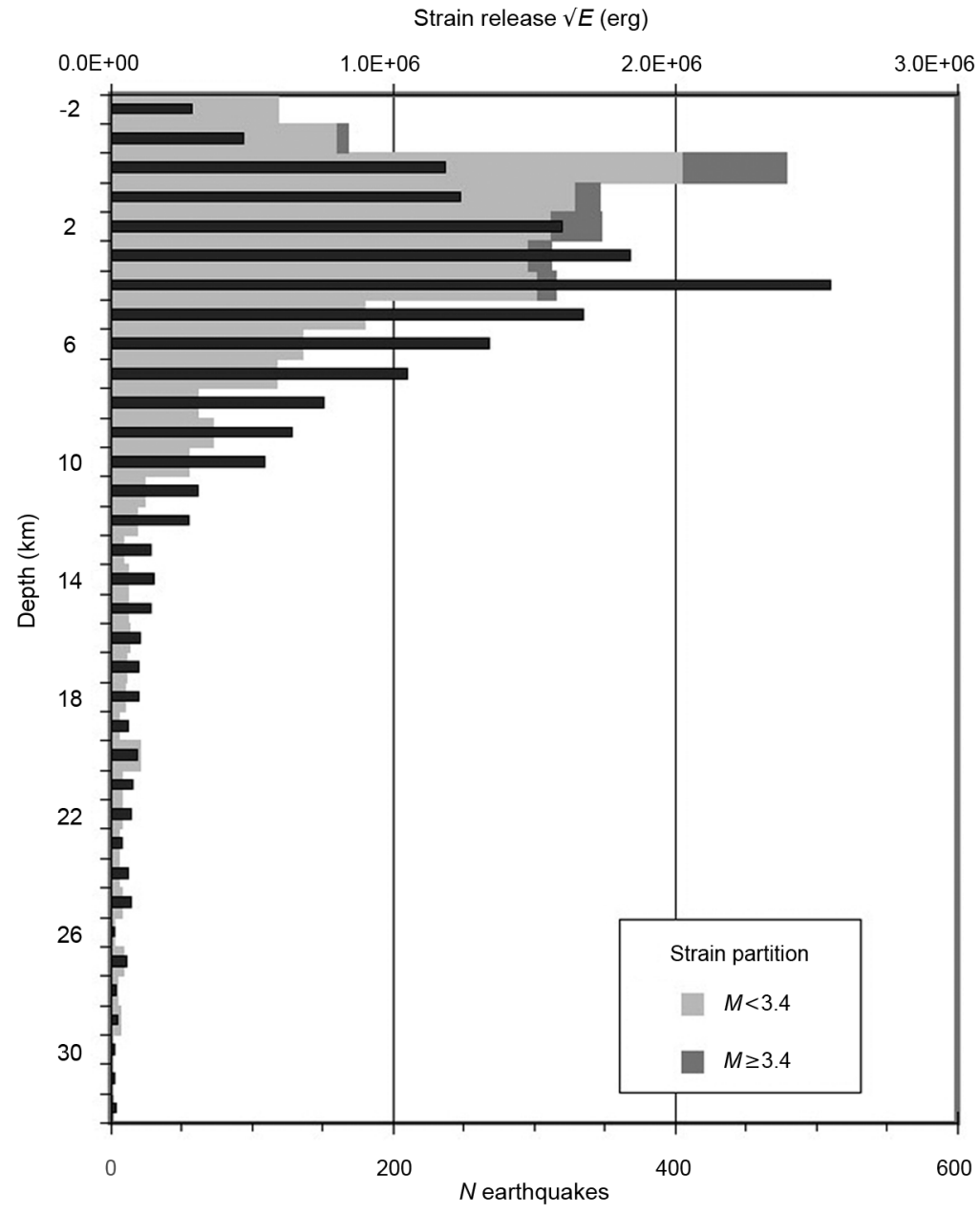

Fig. 3. Distribution of strain release versus depth ( $\mathrm{km}$ below sea level) on Etna's eastern flank obtained from instrumental data (1999-2005, from Gruppo di Lavoro Analisi Dati Sismici, 2005).

Table II. Dataset of the earthquakes selected for the Aeolian Islands. $M_{a w}$, moment magnitude from CPTI Working Group (2004). Source of data: 2) Monachesi and Stucchi (1997); 3) Azzaro (1995).

\begin{tabular}{ccccccccccccc}
\hline \hline Year & Month & Day & Hour & Min & $N_{i p}$ & $I_{0}$ & $M_{L}$ & $M_{a w}$ & Epicentral area & Lat & Long & Ref. \\
\hline 1892 & 3 & 16 & 12 & 38 & 28 & VII-VIII & 5.4 & Alicudi & 38.556 & 14.590 & 2 \\
1894 & 12 & 27 & & & 12 & VII & 5.2 & Filicudi & 38.562 & 14.570 & 2 \\
1916 & 7 & 3 & 23 & 21 & 18 & VI-VII & 5.1 & Stromboli & 38.812 & 15.237 & 2 \\
1926 & 8 & 17 & 01 & 42 & 44 & VII-VIII & & 5.3 & Salina & 38.567 & 14.825 & 2 \\
1930 & 3 & 26 & 10 & 52 & 11 & VII-VIII & & 5.0 & Filicudi & 38.548 & 14.467 & 2 \\
1995 & 7 & 23 & 18 & 44 & 117 & VI & 4.8 & & Filicudi & 38.567 & 14.583 & 3 \\
\hline
\end{tabular}




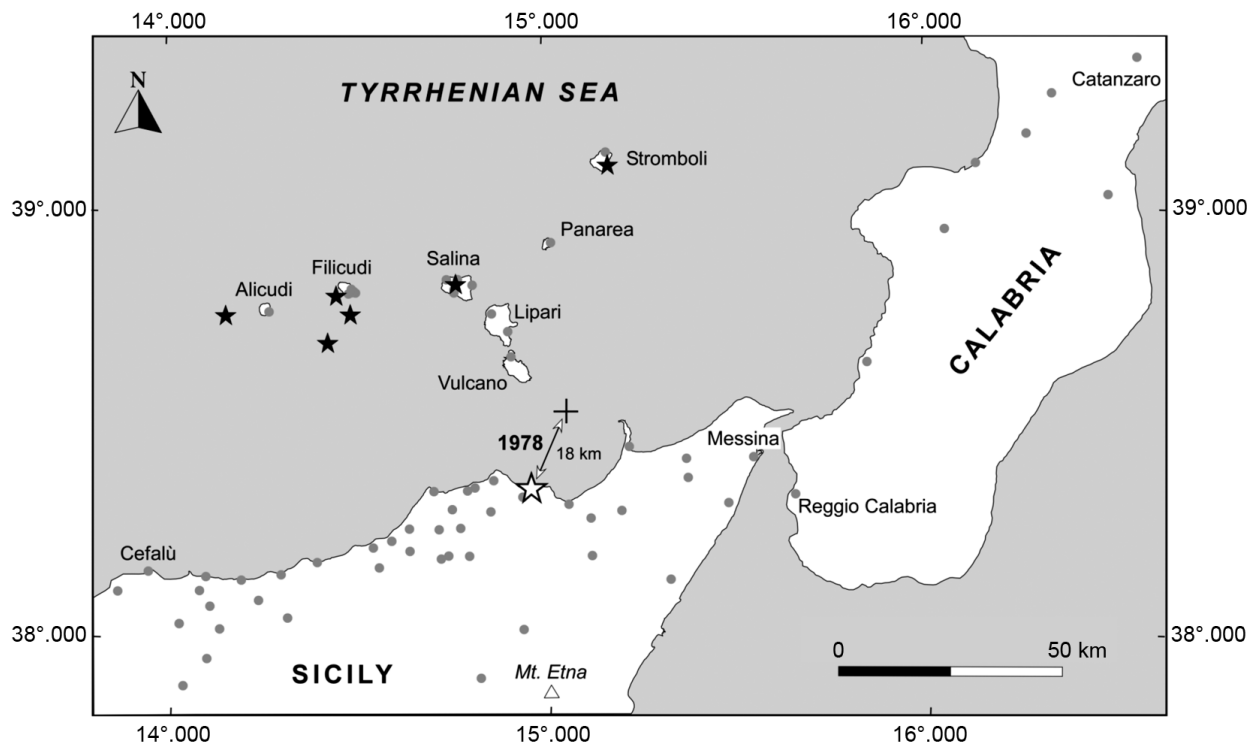

Fig. 4. Distribution of the epicentres and related 117 intensity site observations concerning the 6 earthquakes used for the Aeolian Islands (listed in table II). Symbols as in fig. 2. The white star and the cross represent, respectively, the macroseismic and instrumental epicentres of the 1978 Gulf of Patti earthquake.

Table III. Dataset of the earthquakes selected for the Vesuvius-Ischia district. $M_{a w}$, moment magnitude from CPTI Working Group (2004). Source of data: 4) SGA (2002); 5) Boschi et al. (2000); 6) Cubellis and Marturano (2002).

\begin{tabular}{ccccccccccccc}
\hline \hline Year & Month & Day & Hour & Min & $N_{i p}$ & $I_{0}$ & $M_{L}$ & $M_{a w}$ & Epicentral area & Lat & Long & Ref. \\
\hline 1881 & 3 & 4 & 12 & & 9 & VIII & & 5.4 & Casamicciola & 40.750 & 13.917 & 4 \\
1883 & 7 & 28 & 20 & 25 & 28 & IX & & 5.8 & Casamicciola & 40.750 & 13.880 & 5 \\
1999 & 9 & 10 & 07 & 41 & 48 & VI & 3.6 & & Vesuvius & 40.825 & 14.411 & 6 \\
\hline
\end{tabular}

retrieved from Azzaro (1995), obtaining a dataset of 117 macroseismic observations (fig. 4).

The availability of data for the Neapolitan volcanic district (ZS928) is scant. For Ischia Island only two shock (with $I_{0} \geq$ VIII) that are appropriate for the analysis were found (table III), one reported in the DOM database (Monachesi and Stucchi, 1997) and the other one in SGA (2002), for a total of 37 intensity data. For Vesuvius, just one earthquake of $I_{0}=\mathrm{VI}$ (Cubellis and Marturano, 2002) is available, with 48 macroseismic observations (fig. 5).

Finally, for the Albani Hills (ZS922) the dataset consists of 5 earthquakes with $I_{0} \geq \mathrm{VI}-\mathrm{VII}$ (table IV), all characterised by a significant number of intensity data points retrieved from the DOM and CFTI databases (Monachesi and Stucchi, 1997; Boschi et al., 2000). On the whole, 190 macroseismic observations are available (fig. 6).

\section{Data analysis and results}

In the following, we analyse the presented datasets by plotting, for each volcanic district, the hypocentral distances $D$ of the points versus $\Delta I$, the difference between epicentral $I_{0}$ and site $I_{x}$ intensities. The $I_{0}$ values are retrieved from 
the aforementioned catalogues, and in most cases correspond to the maximum observed intensity. Then some attenuation relationships are compared in order to find the law that empirically best fits data.

\subsection{Etna area}

The intensity data points are not uniformly distributed throughout the Etna area, most of them being located in the eastern sector of the volcano (fig. 2), the most intensively urbanised one. The focal depth used to calculate the hypocentral distance $D$ was defined at $1 \mathrm{~km}$ b.s.l., as indicated by instrumental data (fig. 3). Considering that intensity data are much denser at short distances from the epicentres than at longer ones, we calculated the arithmetic average of $\Delta I$ and the corresponding $95 \%$ confidence intervals, within intervals of $1 \mathrm{~km}$ up to $10 \mathrm{~km}$ of distance, $5 \mathrm{~km}$ up to $20 \mathrm{~km}$ whereas at distances larger

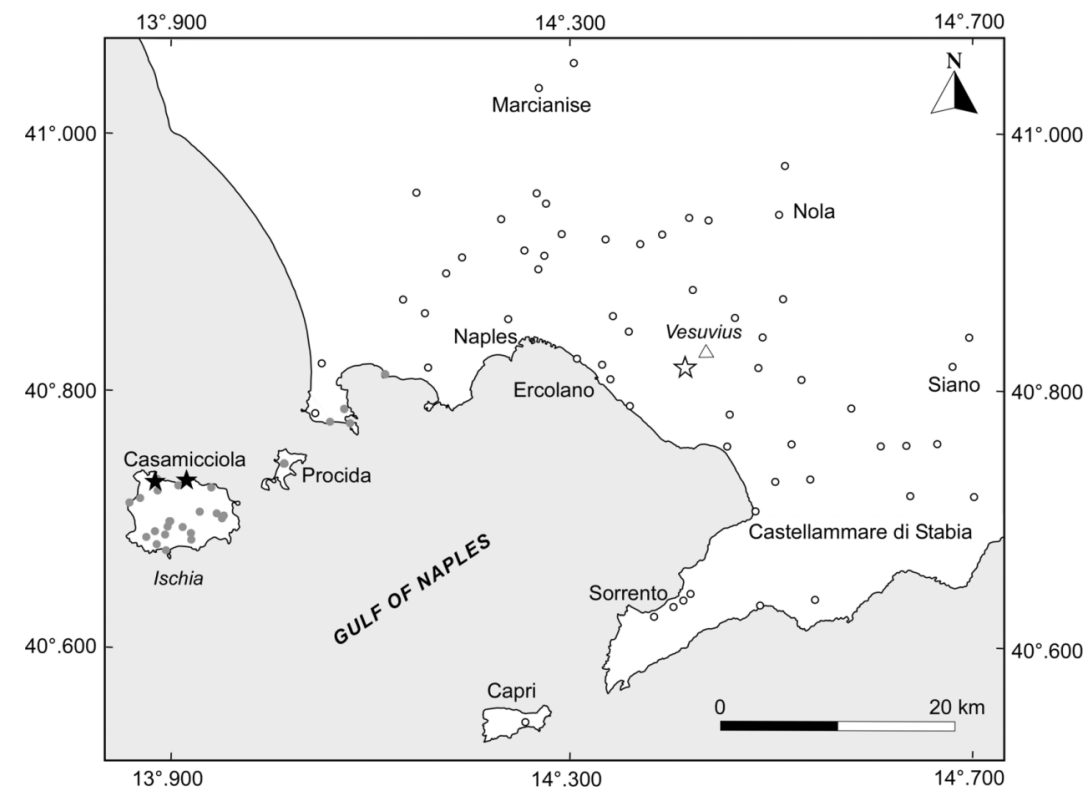

Fig. 5. Distribution of the epicentres and related site intensities of the earthquakes used for the Neapolitan volcanic district (listed in table III). Symbols as in fig. 2: Ischia (black star), 2 earthquakes for 37 site observations; Vesuvius (white star), 1 earthquake for 48 site observations.

Table IV. Dataset of the earthquakes selected for the Albani Hills. $M_{a w}$, moment magnitude from CPTI Working Group (2004). Source of data: 2) Monachesi and Stucchi (1997); 5) Boschi et al. (2000).

\begin{tabular}{cccccccccccc}
\hline \hline Year & Month & Day & Hour & Min & $N_{i p}$ & $I_{0}$ & $M_{a w}$ & Epicentral area & Lat & Long & Ref. \\
\hline 1806 & 8 & 26 & 07 & 35 & 35 & VII-VIII & 5.5 & Albani Hills & 41.720 & 12.730 & 5 \\
1876 & 10 & 26 & 14 & 18 & 29 & VI-VII & 5.0 & Palestrina & 41.827 & 12.784 & 2 \\
1892 & 1 & 22 & & & 81 & VI-VII & 5.2 & Albani Hills & 41.725 & 12.712 & 2 \\
1899 & 7 & 19 & 13 & 18 & 125 & VII & 5.2 & Albani Hills & 41.800 & 12.680 & 5 \\
1927 & 12 & 26 & 15 & 06 & 38 & VII & 5.0 & Albani Hills & 41.700 & 12.700 & 5 \\
\hline
\end{tabular}




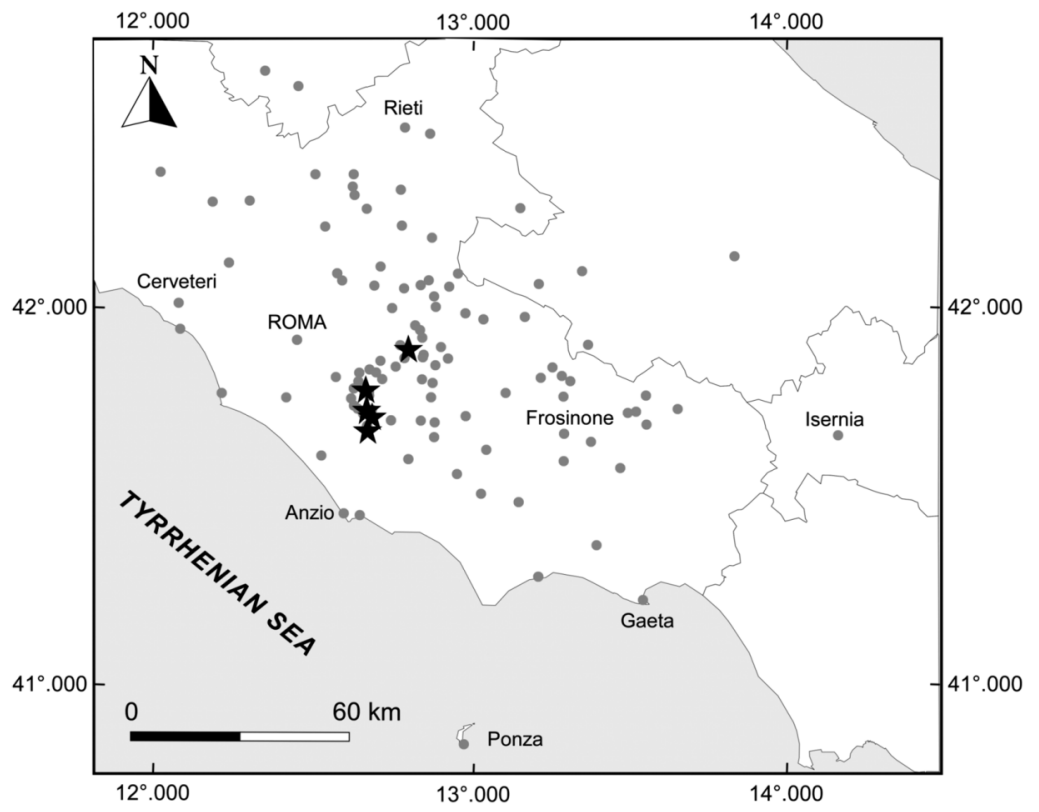

Fig. 6. Distribution of the epicentres and related 190 intensity site observations of the 5 earthquakes analysed for the Albani Hills (listed in table IV). Symbols as in fig. 2.

than $20 \mathrm{~km}$ the step has been increased to $10 \mathrm{~km}$ (fig. 7a).

Since sampling at low intensity sites $\left(I_{x}<\mathrm{IV}\right)$ may be incomplete, data with $I_{x} \leq$ IIII-IV were removed. Therefore, a test to investigate the influence of low-degree incompleteness in the sample, was performed by plotting the average residuals as a function of predicted intensity. The bias is evidenced by systematically negative $\Delta I$ average residuals at low predicted intensities and positive ones at large intensities. The obtained results show that data are incomplete for $\Delta I$ values $\geq 5$, which have been excluded from the analysis.

On average there are more than 75 intensity data in each $\Delta I$ class in the near field $(\leq 10 \mathrm{~km})$, and about 20 in the far field $(>10 \mathrm{~km})$.

Figure $7 \mathrm{~b}$ shows the typical pattern of the shallow Etnean shocks with respect to deeper crustal events such as the 1818 one, the largest $\left(M_{a w}=6.2\right)$ known earthquake located in the area but not related to the shallow volcano-tectonic structures (Azzaro, 2004). In such a case the attenuation is much lower - damage extending up to $50 \mathrm{~km}$ far from the epicentre and the felt area is some hundreds kilometres wide similarly to that of the regional events.

In order to test the best attenuation model, the $\Delta I$ average values were fitted by least-square method using a bi-linear relationship, as done by Gasperini (2001) for the whole Italian dataset, and a logarithmic law (fig. 8a). Furthermore, the coefficients of the Grandori et al. (1987) relationship were re-calculated to verify probable variations with respect to those computed by Peruzza (2000) using a very limited dataset.

The obtained bi-linear relationship is

$$
\Delta I=0.81+0.34 D \text { for } D \leq 8 \mathrm{~km}
$$

$$
\begin{gathered}
\Delta I=0.81+0.34 \times 8+0.02(D-8) \text { for } D>8 \mathrm{~km} \\
R^{2}=0.95
\end{gathered}
$$

where $D$ is the hypocentral distance.

The logarithmic regression is

$$
\Delta I=0.98 \ln (D)+1.01 R^{2}=0.92 \text { for } D \geq 0.4 \mathrm{~km} \text {. }
$$

The Grandori et al. (1987) relationship is 


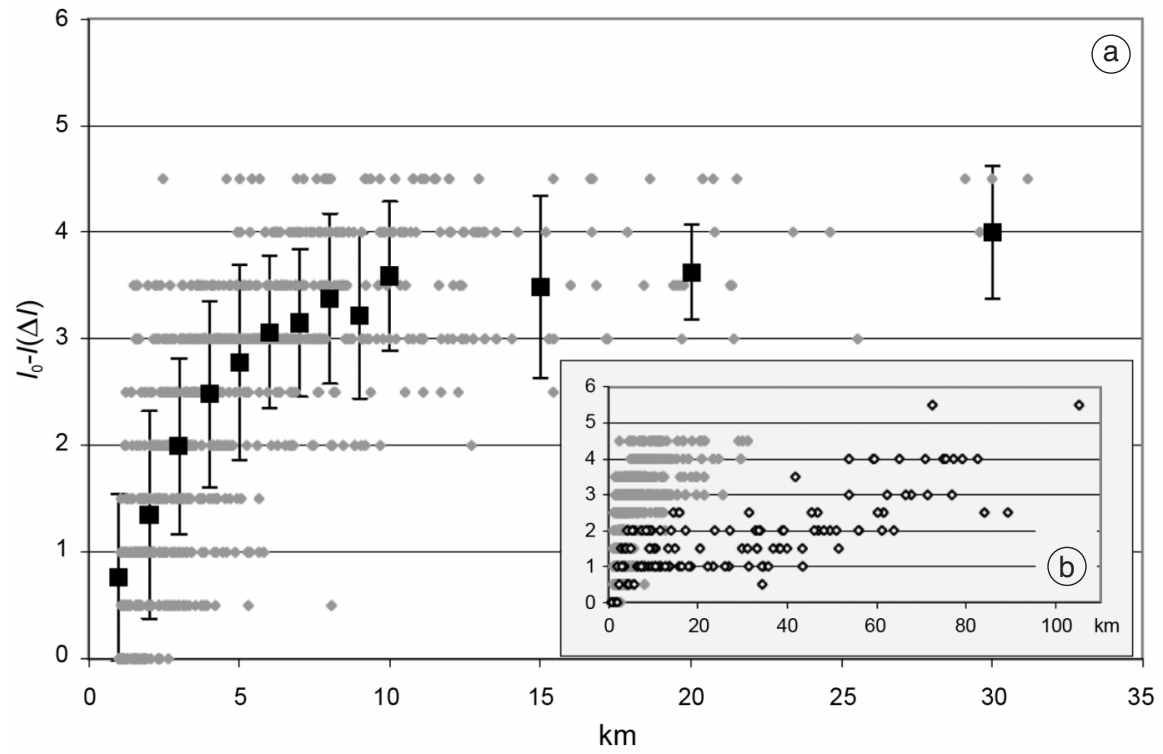

Fig. 7a,b. Etna area. a) Hypocentral distances versus $\Delta I$ (difference between epicentral and site intensities) for the earthquakes used in the analysis (grey diamonds); black squares indicate the arithmetic average of $\Delta I$ and relative standard deviation. b) Comparison between the 1818 earthquake intensity data (black diamonds) with respect to the dataset (grey diamonds).

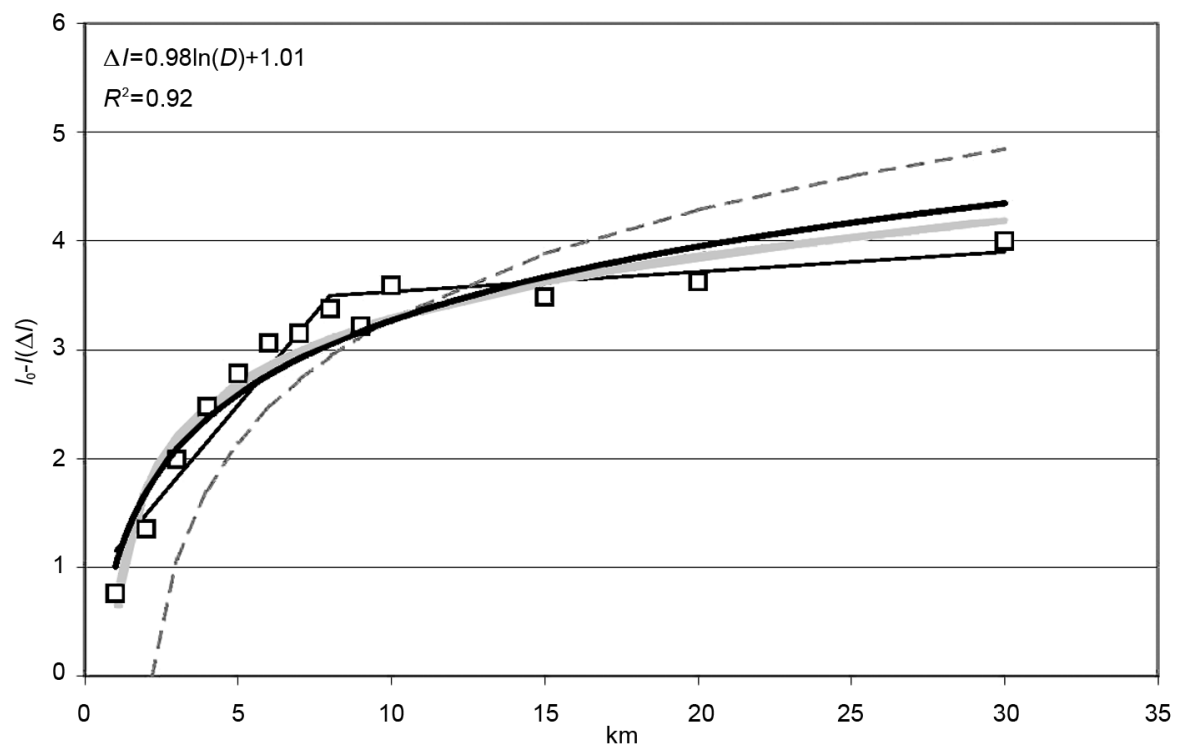

Fig. 8a. Different intensity attenuation relationships for the Etna area: bi-linear (thin line), logarithmic (thick line), Grandori et al. (1987) (grey), Peruzza (2000) (dashed); squares show the arithmetic average of $\Delta I$ in fig. $7 \mathrm{a}$. 


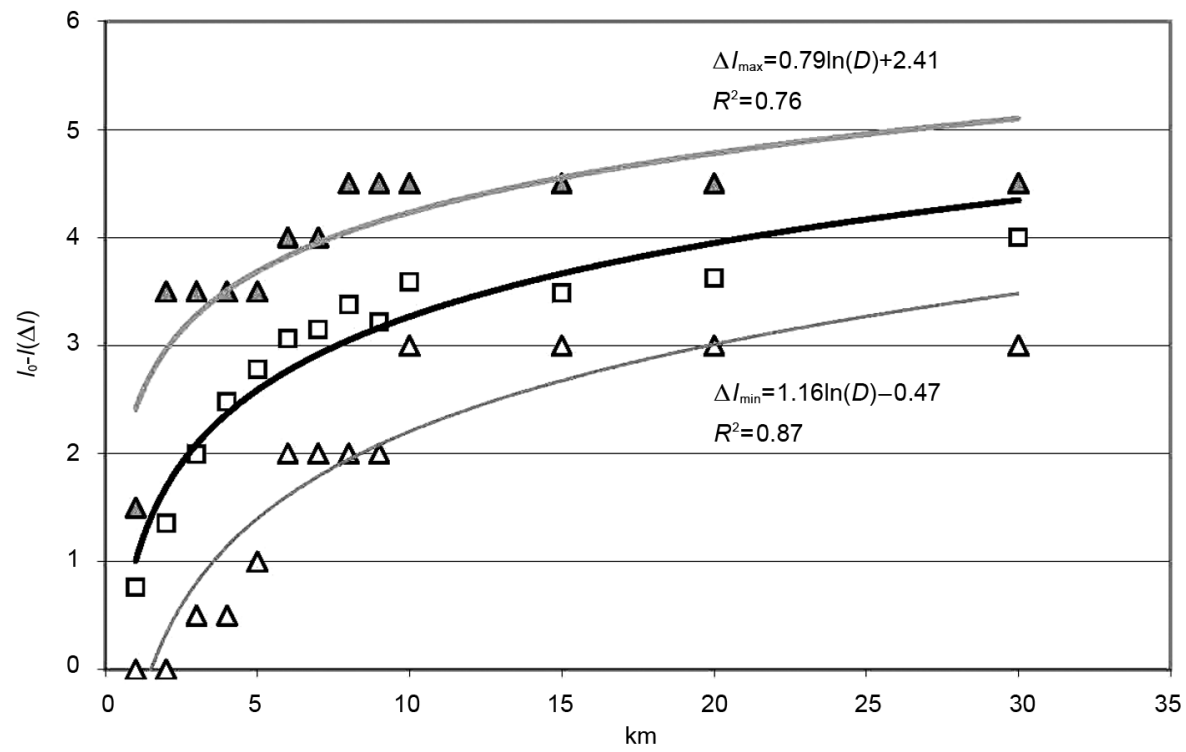

Fig. 8b. Best fits of the logarithmic relationships for maximum, minimum (grey and white triangles) and average values of attenuation; squares show the arithmetic average of $\Delta I$ in fig. $7 \mathrm{a}$.

$$
\Delta I=\frac{1}{\ln \Psi} \ln \left[1+\frac{\Psi-1}{\Psi_{0}}\left(\frac{D}{D_{0}}-1\right)\right]
$$

where $\Psi=3.556, \Psi_{0}=0.460$ and $D_{0}=0.804$, $R^{2}=0.95$.

For all the tested relationships the $R^{2}$ values are comparable. In terms of expected $\Delta I$, there is no great difference between the results obtained from the three relationships. The bi-linear model shows a significant change in coefficients around $8 \mathrm{~km}$ of distance from the epicentre and requires three coefficients to be defined. The Grandori relationship is strongly dependent on three coefficients strictly related to each other and to the epicentral intensity $\left(I_{0}\right)$. Differences in the attenuation trend (fig. 8a) between the Grandori relationship and our logarithmic regression are evident in the near- and far-field (around $10 \mathrm{~km}$ ) as a result of the diverse dataset used by us and Peruzza (2000). So we propose to adopt the logarithmic law as intensity attenuation model in the Etna region because it is simpler, as it requires only two coefficients to be de- fined and it corresponds to a basic attenuation law valid at any distance. For this reason hereafter it was adopted as an appropriate attenuation law also for the other volcanic Italian districts.

The trend of logarithmic regression in fig. 8a does not take into account the source effect. In fact, the attenuation pattern of heavily damaging earthquakes is characterised by a highest intensity area distributed along the fault strike and a rapid decrease of the intensity in the perpendicular direction (fig. 9). Therefore we computed the maximum and minimum values of $\Delta I$ for each distance class, at the corresponding $75 \%$ confidence intervals, obtaining the related logarithmic curves of maximum and minimum attenuation (fig. 8b). In the near and far fields they are parallel to the average attenuation regression but shifted by about 1 intensity degree. These relationships can be adopted to better model hazard scenarios at a local scale of the volcano but for probabilistic assessment at a larger scale (i.e. national seismic mapping), we retain that the use of the logarithmic attenuation regression deriving from the $\Delta I$ average values is more suitable. 


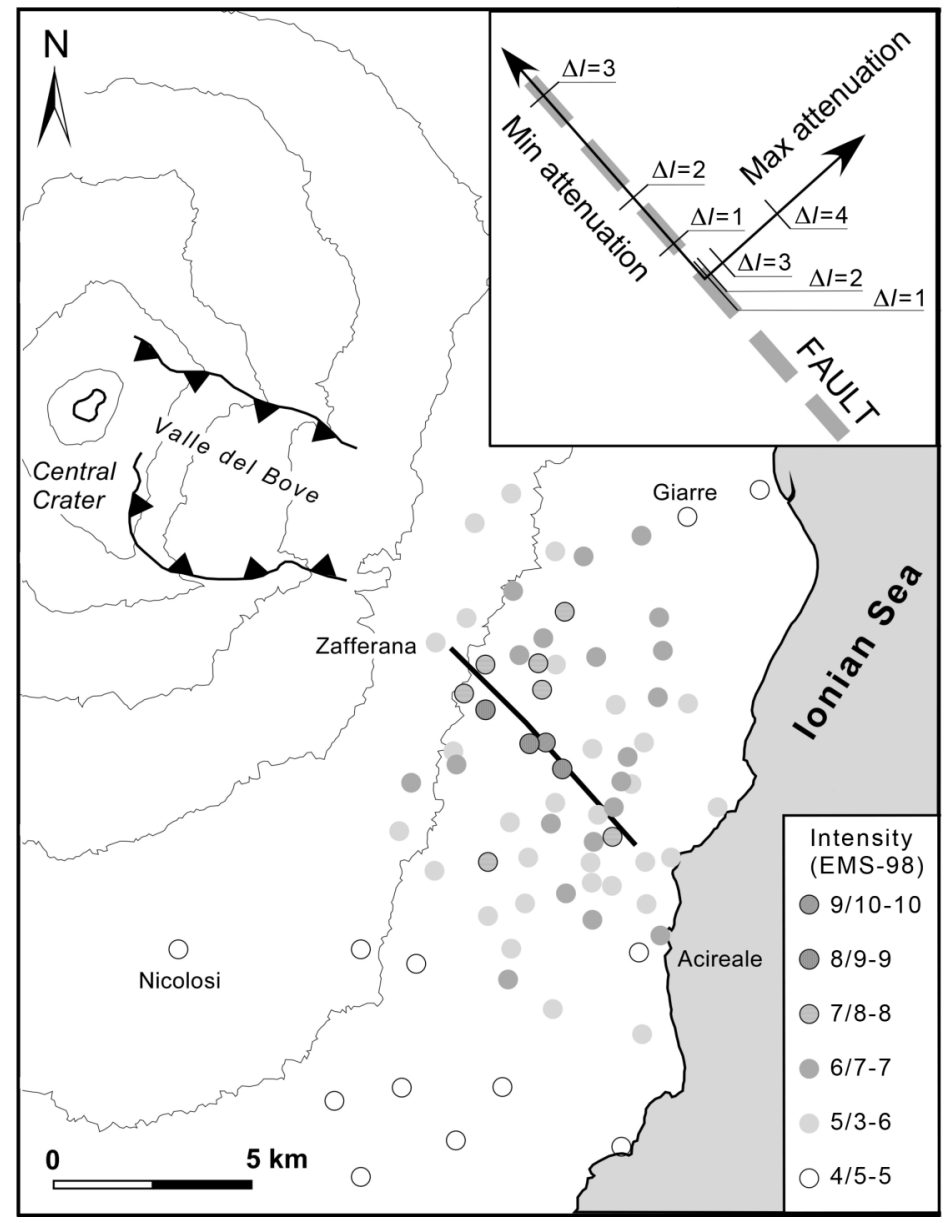

Fig. 9. Intensity map of the 1914 destructive earthquake ( $I_{0}=X$ EMS-98), from Azzaro et al., (2000). Note the maximum intensities elongated astride the causative fault (line in bold), which corresponds to the minimum attenuation. Inset represents the minimum and maximum attenuation trends resulting from the curves of fig. $8 \mathrm{~b}$.

\subsection{Aeolian Islands}

The distribution of the intensity data throughout the Aeolian Islands suffers from a lack of points in the near field due to the presence of the sea and the shape of the archipelago itself (fig. 4). The dataset of this area was filtered by removing all intensity data with $\Delta I \geq 5$ and distance $>150 \mathrm{~km}$ from the epicentre; with regard to the mean hypocentral depth, the value has been fixed at $10 \mathrm{~km}$ b.s.l, as adopted in the seismic zoning for the recent hazard map of Italy (Gruppo di Lavoro, 2004). Figure 10a shows the arithmetic average of $\Delta I$ for classes of hypocentral distances of $5 \mathrm{~km}$ up to $20 \mathrm{~km}$ of distance, whereas at distances larger than $20 \mathrm{~km}$ the step has been increased to $10 \mathrm{~km}$, using the same procedure described above. Figure 10b shows the calculated logarithmic attenuation relationship

$$
\Delta I=1.28 \ln (D)-2.39 R^{2}=0.89 \text { for } D \geq 6.5 \mathrm{~km} \text {. }
$$



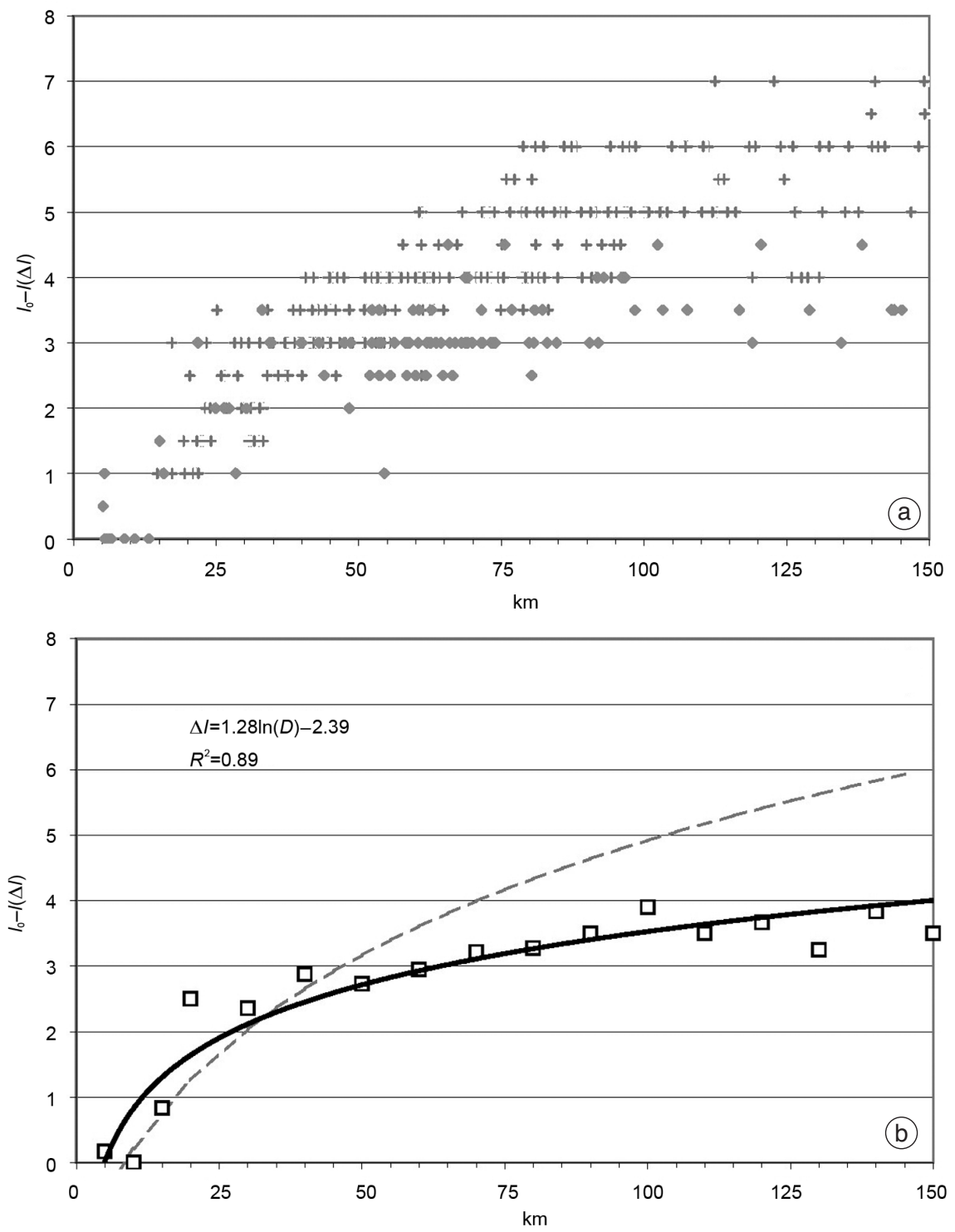

Fig. 10a,b. Aeolian Islands. a) Hypocentral distances versus $\Delta I$ for the earthquakes used in the analysis (diamonds) and comparison with the 1978 Gulf of Patti earthquake intensity data (crosses). b) Best fits (solid line) of the logarithmic relationship for the arithmetic average of $\Delta I$ (squares) and comparison with the Peruzza (2000) equation (dashed).

The $R^{2}$ is lower than that of the Etna area since the curve in the first $25 \mathrm{~km}$ is based only on the average of 4 data. By comparison, the data of the 1978 earthquake used by Peruzza (2000) to com- pute the attenuation model, are also represented. In this case, the epicentral distances are computed considering the instrumental epicentre, located in the sea in the Gulf of Patti. The regression 
obtained for the selected events differs from the attenuation pattern of the regional 1978 earthquake mainly in the far field, over $30 \mathrm{~km}$ of distance.

\subsection{Ischia and Vesuvius}

The distribution of the average values of $\Delta I$ for the Neapolitan volcanic district is shown in
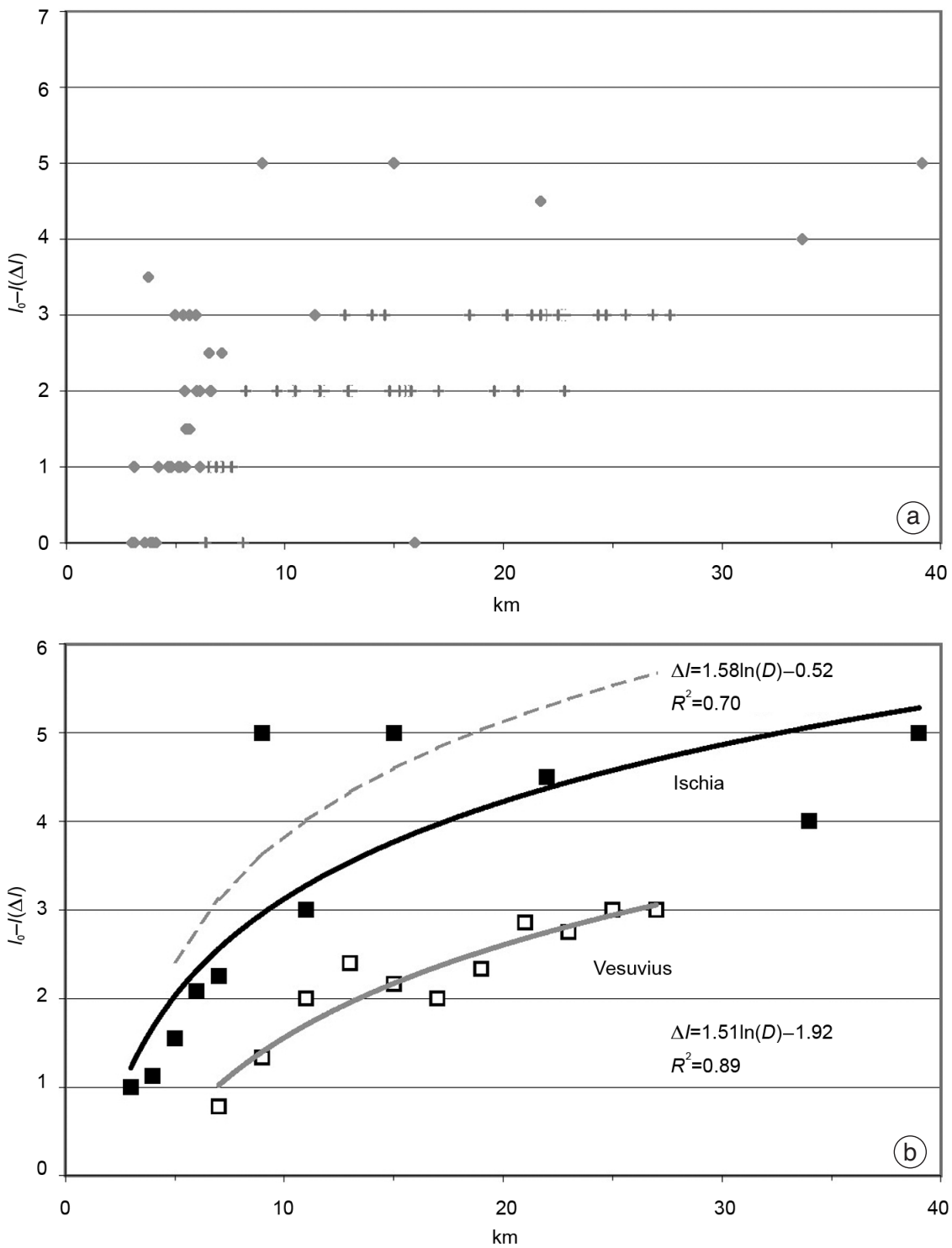

Fig. 11a,b. Neapolitan volcanic district. a) Hypocentral distances versus $\Delta I$ for the earthquakes used in the analysis: Ischia, diamonds; Vesuvius, crosses. b) Logarithmic relationships for the arithmetic average of $\Delta I$ (squares) for Ischia and Vesuvius and comparison with the Peruzza (2000) equation (dashed). 
fig. 11a. The intensity dataset available for this area is rather poor, consisting of just two earthquakes for Ischia and one for Vesuvius (table III). In particular, only the 1999 event is known for this volcano (local magnitude $M_{L}=3.6$ and focal depth about $4 \mathrm{~km}$ b.s.l.), the largest event occurring since the last eruption in 1944 (Del Pezzo et al., 2004). Intensity observations were
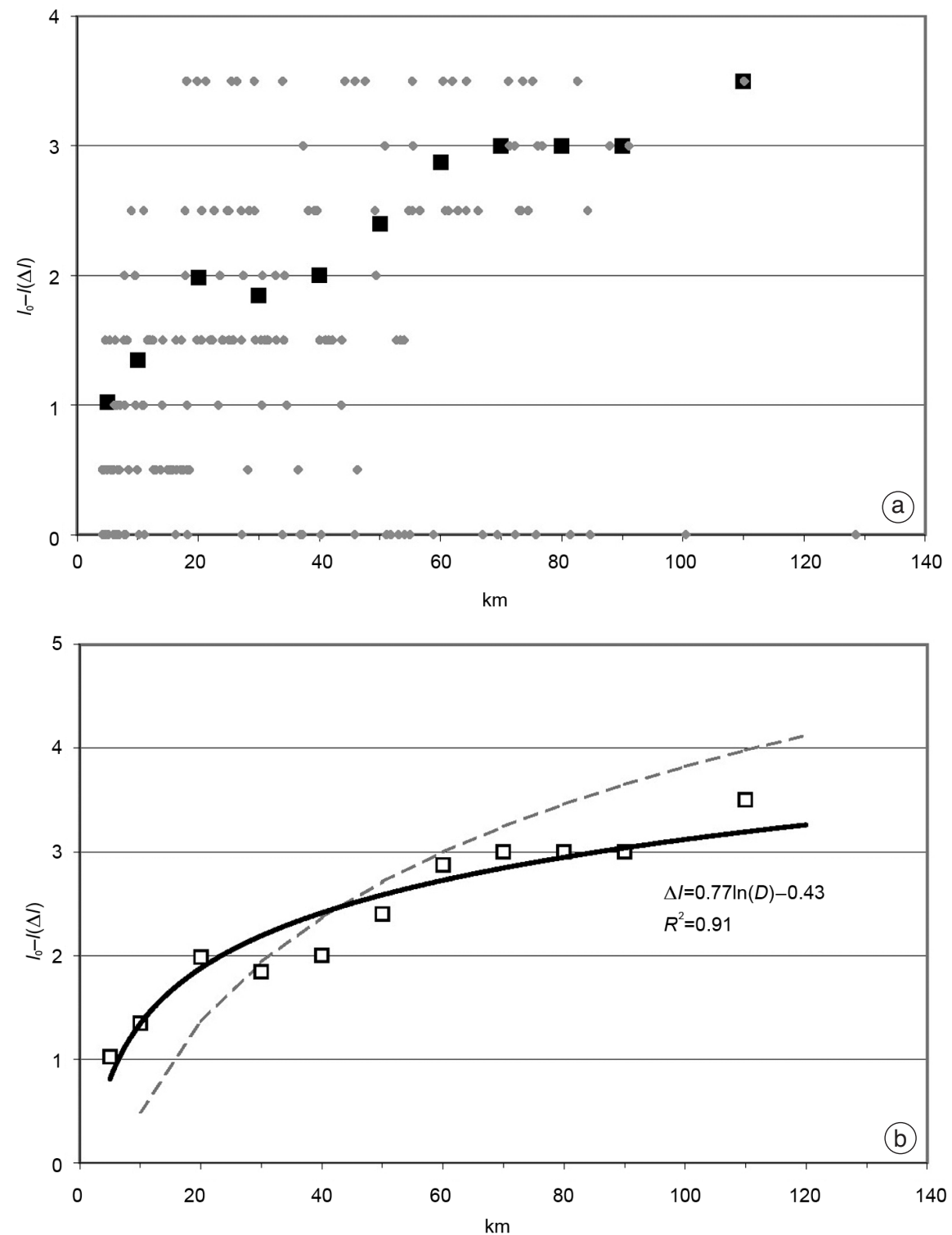

Fig. 12a,b. Albani Hills. a) Hypocentral distances versus $\Delta I$ for the earthquakes used in the analysis (diamonds) and arithmetic average of $\Delta I$ (squares). b) Logarithmic relationship for the average values and comparison with the Peruzza (2000) equation (dashed). 
filtered by removing all data with $\Delta I \geq 5$ and the focal depth was fixed at $3 \mathrm{~km}$ b.s.l according to the recent seismogenic zoning (Gruppo di Lavoro, 2004). Given the small distances involved as on Etna, intervals of hypocentral distances of $1 \mathrm{~km}$ and $2 \mathrm{~km}$, respectively, for Ischia and Vesuvius have been adopted. The results suggest probable differences in the attenuation pattern of the two areas, considered as one in the previous study by Peruzza (2000). Figure 11b shows the attenuation relationships resulting for Ischia and Vesuvius

$\Delta I=1.58 \ln (\mathrm{D})-0.52 \quad R^{2}=0.70$ for $D \geq 1.4 \mathrm{~km}$ (Ischia)

$\Delta I=1.51 \ln (\mathrm{D})-1.92 R^{2}=0.89$ for $D \geq 3.6 \mathrm{~km}$ (Vesuvius).

Their significance from the statistical point of view is low compared with the other studied areas because of the few observations available. The relationship obtained for Ischia is fairly similar to that computed by Peruzza (2000) for the entire seismogenic zone of Ischia-Vesuvius, based on the 1883 Casamicciola earthquake. On the contrary, the intensity attenuation curve for Vesuvius appears very different, with a trend considerably lower than that of Ischia. Although based just on one earthquake, this result suggests that the macroseismic attenuation in the two areas should be treated separately.

\subsection{Albani Hills}

The distribution of the intensity data considered for the district of the Latium volcanoes is fairly dense. The dataset was filtered by removing all intensity data with $\Delta I \geq 4$ and the focal depth was fixed at $4 \mathrm{~km}$ b.s.l. according to Gruppo di Lavoro (2004). The computed arithmetic average of $\Delta I$ was done selecting classes of hypocentral distances of $5 \mathrm{~km}$ up to $10 \mathrm{~km}$ and of $10 \mathrm{~km}$ in the far field (fig. 12a). $12 b$

The resulting regression is presented in fig.

$$
\Delta I=0.77 \ln (D)-0.43 R^{2}=0.91 \text { for } D \geq 1.7 \mathrm{~km} \text {. }
$$

The value of the correlation coefficient is, among the studied cases, the highest one apart from that obtained for the Etnean dataset. With respect to the attenuation curve calculated by Peruzza (2000), our relationship shows a higher attenuation of macroseismic intensity within the first $50 \mathrm{~km}$ of distance and a lesser one beyond this value.

\section{Concluding remarks}

The analysis carried out allowed us to investigate the features of macroseismic attenuation in the Italian volcanic areas in detail, disclosing some differences among them but also analogies. Using an upgraded intensity dataset, more complete than the one adopted by previous studies, intensity attenuation laws have been derived from empiric models that fit data using the $\Delta I$ average values (difference between epicentral $I_{0}$ and site $I_{x}$ intensities) by least-square method and results compared with those by Peruzza (2000), based on a «representative» event for each seismogenic zone. For the Etnean area, in particular, due to the large amount of data, it

Table V. Summary of intensity attenuation laws obtained in this study.

\begin{tabular}{cccc}
\hline \hline Area & Logarithmic regressions & $R^{2}$ & Valid for $D(\mathrm{~km}) \geq$ \\
\hline Etna & $\Delta I=0.98 \ln (D)+1.01$ & 0.92 & 0.4 \\
Aeolian Islands & $\Delta I=1.28 \ln (D)-2.39$ & 0.89 & 6.5 \\
Ischia & $\Delta I=1.58 \ln (D)-0.52$ & 0.70 & 1.4 \\
Vesuvius & $\Delta I=1.5 \ln (D)-1.92$ & 0.89 & 3.6 \\
Albani Hills & $\Delta I=0.77 \ln (D)-0.43$ & 0.91 & 1.7 \\
\hline
\end{tabular}




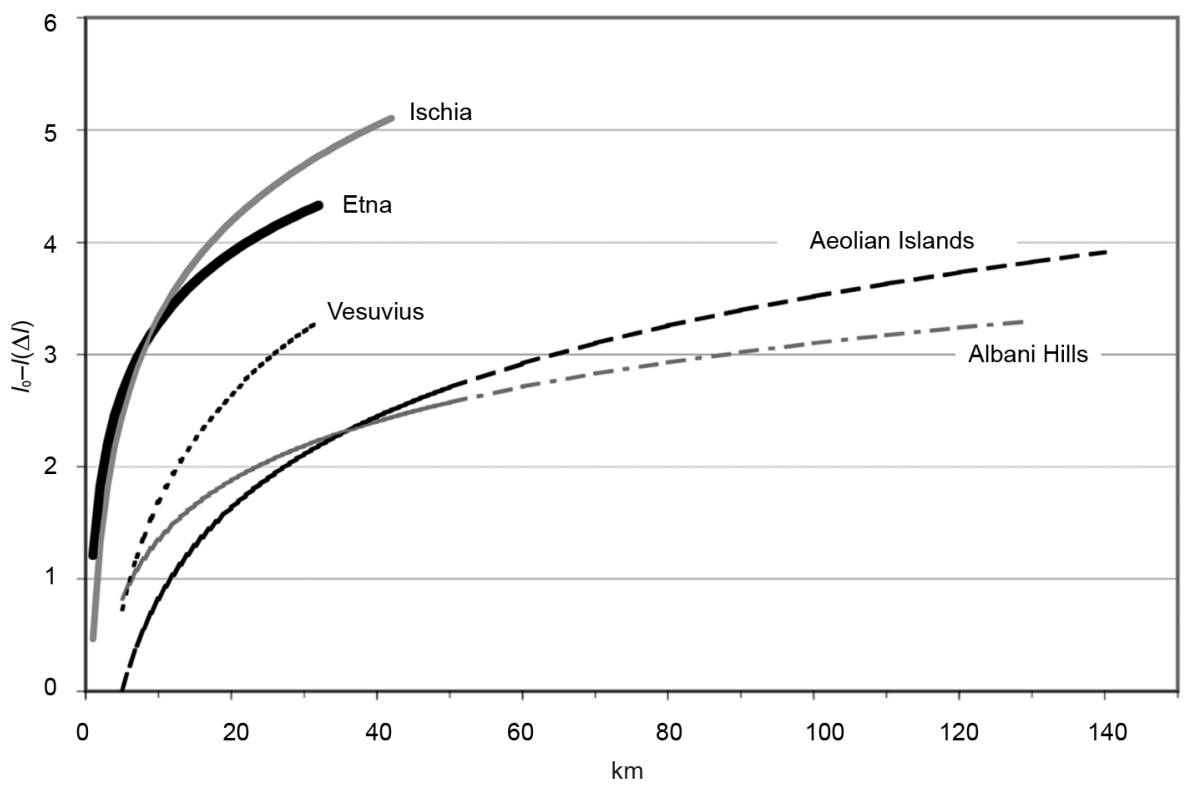

Fig. 13. Comparison of the intensity attenuation relationships obtained for the Italian volcanic districts.

was possible to test the best attenuation model using bi-linear and logarithmic regressions, to verify the source effect on the attenuation and to re-calculate the coefficients of the Grandori et al. (1987) relationship. Among the tested relationships the logarithmic one is simple and fairly stable, so it was adopted as a representative intensity attenuation law also for the other volcanic Italian districts.

By comparing the relationships (table V) computed for each volcanic area (fig. 13), the laws obtained for Etna and Ischia are very similar and show the highest intensity attenuation. This behaviour does not seem to be so evident for Vesuvius, whose curve on the average presents the same trend of the attenuation but over longer distances. A reason for the lower attenuation rate in this area may depend on the fact that the hypocentre of the earthquake used for calibrating the attenuation relationship is located underneath the volcanic edifice inside the carbonate basement (Del Pezzo et al., 2004), a medium characterised by high rigidity. In the Etna region, most of the shallow earthquakes are located in the basement, but the occurrence of less compact rocks such as clayey and flyschioid terrains (Di Stefano and Branca, 2002) may account for a higher attenuation of the seismic energy in the medium.

Finally, the relationships obtained for the Aeolian Islands and Albani Hills (fig. 13) are clearly different from the others, presenting a very low intensity attenuation rate.

In general, all computed relationships show a higher attenuation rate in the near field and lower attenuation in the far field with respect to the laws used so far. The application of these laws should allow a more careful hazard assessment in Italian volcanic areas.

\section{Acknowledgements}

The authors are grateful to P. Gasperini and to an anonymous referee for their useful suggestions which improved the original paper. This work was funded by Italian Dipartimento della Protezione Civile in the frame of the 
2004-2006 Agreement with Istituto Nazionale di Geofisica e Vulcanologia - INGV (Seismological Project S1).

\section{REFERENCES}

Albarello, D. and V. D'Amico (2004): Attenuation relationship of macroseismic intensity in Italy for probabilistic seismic hazard assessment, Boll. Geofis. Teor. Appl., 45 (4), 271-284.

AzZaro, R. (1995): Studio macrosismico dei terremoti di Trapani del 29 maggio e di Filicudi del 23 luglio 1995, in Proceedings of the 14th GNGTS Meeting, 23-25 October 1995, Roma, Italy, 1, 197-204.

AzZARo, R. (2004): Seismicity and active tectonics in the Etna region: constraints for a seismotectonic model, in Mt. Etna: Volcano Laboratory, edited by A. BonaCcorso, S. Calvari, M. Coltelli, C. Del Negro and S. FALSAPERLA, Am. Geophys. Un., 143, 205-220.

AzZARO, R. and M.S. BARBANO (1997): Intensity-magnitude relationship for the Mt. Etna area (Sicily), Acta Volcanol., 9 (1/2), 15-21.

Azzaro, R., M.S. Barbano, B. Antichi and R. Rigano (2000): Macroseismic catalogue of Mt. Etna earthquakes from 1832 to 1998, Acta Volcanol., 12 (1), 3-36 (with CD-ROM).

AzZaro, R., S. D'Amico, A. Mostaccio and L. Scarfi (2002): Terremoti con effetti macrosismici in Sicilia orientale - Calabria meridionale nel periodo Gennaio 1999 - Dicembre 2001, Quad. Geofis., 27, pp. 59.

Azzaro, R., S. D'Amico, A. Mostaccio and L. Scarfì (2006): Terremoti con effetti macrosismici in Sicilia orientale nel periodo Gennaio 2002-Dicembre 2005, Quad. Geofis., 41, pp. 62.

Berardi, R., L. Magri, M. Mucciarelli, C. Petrungaro and L. ZANETTI (1994): Mappe di Sismicità per l'Area Italiana (ENEL, Roma), pp. 66.

Bianco, F., M. Castellano, E. Del Pezzo and J.M. Ibanez (1999): Attenuation of short period seismic waves at Mt. Vesuvius, Italy, Geophys. J. Int., 138, 67-76.

BlaKe, A. (1941): On the estimation of focal depth from macroseismic data, Bull. Seismol. Soc. Am., 31, 225-231.

Boschi, E., E. Guidoboni, G. Ferrari, D. Mariotti, G. VALENSISE and P. GASPERINI (2000): Catalogue of strong Italian earthquakes from 461 b.C. to 1997, Ann. Geofis., 43 (4), 609-868 (available on line at http://storing.ingv.it/ $\mathrm{cft} /$ ).

Ciccotti, M., N. Negri, L. Sassi, G. GonZato and F. MuLARGIA (2000): Elastic and fracture parameters of Etna, Stromboli, and Vulcano lava rocks, J. Volcanol. Geotherm. Res., 98, 209-217.

Cornell, C.A. (1968): Engineering seismic risk analysis, Bull. Seismol. Soc. Am., 58, 1583-1606.

CPTI Working Group (2004): Catalogo Parametrico dei Terremoti Italiani, version 2004 (INGV, Bologna), (available on line at http://emidius.mi.ingv.it/CPTI/).

Cubellis, E. and A. Marturano (2002): Mt. Vesuvius: a macroseismic study of the earthquake of 9 October 1999, J. Volcanol. Geotherm. Res., 118, 339-351.

Del Pezzo, E., S. Gresta, D. Patanè, G. Patanè and G.
SCARCELLA (1987): Attenuation of short period seismic waves at Etna as compared to other volcanic areas, Pure Appl. Geophys., 125, 1039-1050.

Del Pezzo, E., F. Bianco and G. Saccarotti (2004): Seismic source dynamics at Vesuvius volcano, Italy, J. Volcanol. Geotherm. Res., 133, 23-39.

Di Stefano, A. and S. BRAnca (2002): Long-term uplift rate of the Etna volcano basement (Southern Italy) based on biochronological data from Pleistocene sediments, Terra Nova, 14, 61-68.

GASPERINI, P. (2001): The attenuation of seismic intensity in Italy: a bi-linear shape indicates the dominants of deep phases at epicentral distances longer than $45 \mathrm{~km}$, Bull. Seismol. Soc. Am., 91, 826-841.

Grandori, G., F. Perotti and A. TAgliani (1987): On the attenuation of macroseismic intensity with epicentral distance, in 'Ground motion and Engineering Seismology, edited by Cakmak', Proceedings of 3rd Int. Conf. on Soil Dynamics and Earthquake Eng., 1986, Princeton U.S.A. (Elsevier), 581-594.

GRUPPO DI LAVORO (2004): Redazione della mappa di pericolosità sismica prevista dall'Ordinanza PCM 3274 del 20 marzo 2003, Final report for the Civil Protection Department (INGV, Milano-Roma), 5 appendices, pp. 65.

GRUPPO Di LAVORo ANAlisi Dati Sismici (2005): Terremoti Recenti Localizzati con la Rete Sismica della Sicilia Orientale (INGV, Catania), (available on line at http://www.ct.ingv.it/Sismologia/analisti/default.asp).

Magri, L., M. Mucciarelli and D. Albarello (1994): Estimates of site seismicity rates using ill-definition macroseismic data, Pure Appl. Geophys., 143 (4), 617-632.

Margottini, C. (1993): La Magnitudo dei Terremoti Italiani del XX Secolo (ENEA, Roma), pp. 57.

Martinez-Arevalo, C., F. Bianco, J.M. IbaneZ and E. Del Pezzo (2003): Shallow seismic attenuation and shearwave splitting in the short period range of Deception Island volcano (Antarctica), J. Volcanol. Geotherm. Res., 128, 89-113.

Mayeda, K., S. Koyanagi, M. Hoshiba, K. AKI and I. Zeng (1992): A comparative study of scattering intrinsic and coda Q-1 for Hawaii, Long Valley and Central California between 1.5 and $15 \mathrm{~Hz}$, J. Geophys. Res., 97, 66436659.

Meletti, C., E. Patacca and P. Scandone (2000): Construction of a seismotectonic model: the case of Italy, Pure Appl. Geophys., 157, 11-35.

MonACHESI, G. and M. STUCCHI (1997): DOM 4.1: an Intensity Database of Damaging Earthquakes in the Italian Area (GNDT-CNR, Milano), (available on line at http://emidius.itim.mi.cnr.it/DOM).

Novelo-Casanova, D.A. and A. Martínez-Bringas (2005): A seismic attenuation zone below Popocatépetl volcano inferred from coda waves of local earthquakes, Geofis. Inter., 44 (2), 177-186.

PATANE, D. and E. GiAmPICCOLO (2004): Faulting processes and earthquake source parameters at Mount Etna: state of art and perspective, in Mt. Etna: Volcano Laborato$r y$, edited by A. Bonaccorso, S. Calvari, M. ColtelLi, C. Del Negro and S. Falsaperla, Am. Geophys. Un., 143, 167-189.

PeruZZA, L. (2000): Macroseismic attenuation relationships of Italian earthquakes for seismic hazard assess- 
ment purposes, Boll. Geofis. Teor. Appl., 41 (1), 31-48. SGA (2002): Ricerche, revisioni e confronti. Terremoti storici, Rapporto Tecnico (Incarico INGV-MI 01/2002, 25 Gennaio 2002, RPT 248/02, Bologna), pp. 214 (with CD-ROM)

Slejko, D., L. Peruzza and A. Rebez (1998): Seismic hazard maps of Italy, Ann. Geofis., 41 (2), 183-214.
Vilardo, G., G. De Natale, G. Milano and U. Coppa (1996): The seismicity of Mt. Vesuvius, Tectonophysics, 261, 127-138.

(received January 15, 2006 accepted August 20, 2006) 